\title{
Personal Knowledge Management
}

The Role of Web 2.0 Tools for Managing Knowledge at Individual and Organisational Levels

Razmerita, Liana; Kirchner, Kathrin; Sudzina, Frantisek

\author{
Document Version \\ Final published version \\ Published in: \\ Online Information Review
}

DOI:

$10.1108 / 14684520911010981$

Publication date:

2009

License

CC BY-NC-ND

Citation for published version (APA):

Razmerita, L., Kirchner, K., \& Sudzina, F. (2009). Personal Knowledge Management: The Role of Web 2.0 Tools for Managing Knowledge at Individual and Organisational Levels. Online Information Review, 33(6), 1021-1039. https://doi.org/10.1108/14684520911010981

Link to publication in CBS Research Portal

\section{General rights}

Copyright and moral rights for the publications made accessible in the public portal are retained by the authors and/or other copyright owners and it is a condition of accessing publications that users recognise and abide by the legal requirements associated with these rights.

\section{Take down policy}

If you believe that this document breaches copyright please contact us (research.lib@cbs.dk) providing details, and we will remove access to the work immediately and investigate your claim. 
Post print of Online Information Review, 2009, Volume 33, Number 6, Page(s) 1021-1039

Stable URL to publisher: http://dx.doi.org/10.1108/14684520911010981

\title{
Personal Knowledge Management: The role of Web 2.0 tools for managing knowledge at individual and organisational levels
}

\author{
Liana Razmerita* \\ Department of International Language Studies and Computational Linguistics \\ Copenhagen Business School \\ Frederiksberg, Denmark
}

Kathrin Kirchner

Department of Business Information Systems

Friedrich-Schiller-University

Jena, Germany

Frantisek Sudzina

Centre of Applied Information and Communication Technology

Copenhagen Business School

Frederiksberg, Denmark

\begin{abstract}
About the authors
*Liana Razmerita, the corresponding author, is Assistant Professor at the Copenhagen Business School. She holds a doctorate in computer science from Université Paul Sabatier in Toulouse. Her doctoral research was done in the context of an Information Society Technology (IST), European Commission-funded project, at the Centre of Advanced Learning Technologies, INSEAD. Previous publications include more than 30 refereed journal articles, book chapters and conference papers in domains such as knowledge management, user modelling, e-learning and e-government. Email: lr.isv@cbs.dk

Kathrin Kirchner holds a post-doctoral position in the Department of Business Information Systems, Friedrich-Schiller-University, and works in the fields of data analysis, decision support and knowledge management. She completed her doctorate in 2006 at FriedrichSchiller-University on spatial decision support systems for rehabilitating gas pipeline networks. Until 2001 she worked as a lecturer in computer science.
\end{abstract}


Frantisek Sudzina finished his studies in economics and business management at the University of Economics Bratislava in 2000, in mathematics in 2004, and in computer science in 2006. He completed his doctorate in 2003 on the topic of management information systems and business competitiveness. Since 2007 he has been an assistant professor at Copenhagen Business School.

Article received 20 April 2008

Revision approved for publication 7 July 2009

\begin{abstract}
Purpose - This paper discusses new approaches for managing personal knowledge in the Web 2.0 era. We question whether Web 2.0 technologies (social software) are a real panacea for the challenges associated with the management of knowledge. Can Web2.0 reconcile the conflicting interests of managing organisational knowledge with personal objectives? Does Web 2.0 enable a more effective way of sharing and managing knowledge at the personal level?

Design /methodology/approach - Theoretically deductive with illustrative examples.

Findings - Web 2.0 plays a multifaceted role for communicating, collaborating, sharing and managing knowledge. Web 2.0 enables a new model of PKM that includes formal and informal communication, collaboration and social networking tools. This new PKM model facilitates interaction, collaboration and knowledge exchanges on the web and in organisations.
\end{abstract}

Practical implications - Based on these findings professionals and scholars will gain a better understanding of the potential role of Web 2.0 technologies for harnessing and managing personal knowledge. The paper provides concrete examples of how Web 2.0 tools are currently used in organisations.

Originality/value - As Web 2.0 has become integrated in our day-to-day activities, there is a need to further understand the relationship between Web 2.0 and Personal Knowledge Management (PKM). 
Keywords - Web 2.0, Social web, Social networks, Knowledge management, Personal knowledge management

Type of paper - Research paper

\section{Introduction and background}

While Knowledge Management (KM) generally focuses on the process of managing organisational knowledge, Personal Knowledge Management (PKM) focuses on the individual for the quest to learn, work efficiently or socialise. An important aspect of PKM is to allow the individual to better manage their knowledge processes and interaction, collaboration and knowledge exchanges with others. PKM reflects the goal of supporting individual knowledge workers rather than establishing an organisational approach. Initially PKM was approached as a framework to organise the knowledge of individuals that is important for individuals (Frand and Hixson, 1999). The concept has evolved over time and involves organising personal information, making sense of information, negotiating meaning, creating new ideas, developing networks, collaborating, sharing and interacting (Efimova, 2004; Wright, 2005). PKM environments integrate individual work environments and infrastructures to support joint creation, distribution, sharing and application of knowledge (Maier and Sametinger, 2004).

Web 2.0 (O’Reilly, 2005) or the Social Web has introduced new concepts and tools that are able to operationalise a more social-centric vision. Online social networking systems, such as LinkedIn, MySpace and Facebook, allow people to manage their interaction with others on a massive scale. Blogs, microblogs (e.g., Twitter) and instant messaging tools, such as Skype, have provided new communication tools to interact more effectively with others in opened communities. Finally, radically new tools have emerged, such as Wikis (Wikipedia) and social bookmarking (del.icio.us), aimed at directly supporting PKM and fostering collective intelligence. This perspective has appeared so relevant and so promising that many specialists consider this approach to be the future of knowledge management, hoping that these new tools will contribute to realising the challenge of managing knowledge (Kakizawa, 2007; McAfee, 2006; Shimazu and Koike, 2007). Yet this perspective raises a number of questions related to the application of a vision that was born from the need to incorporate more of the 
social dimension (Nabeth et al., 2002; Thomas et al., 2001) and to better fit the individual needs of knowledge workers (Razmerita, 2005b).

PKM on Web 2.0 is achieved by a set of tools that allow people to create, codify, organise and share knowledge, but also to socialise, extend personal networks, collaborate on organising knowledge and create new knowledge. This paper follows this broader definition of PKM.

This paper discusses the evolution of the $\mathrm{KM}$ and PKM concepts, taking into account technological advancements and focussing on the personal dimension. Web 2.0 tools foster personal knowledge processes and satisfaction, allowing people to be more effective, and supporting knowledge sharing and virtual interaction through easy to use, collaborative tools. In particular, these PKM tools are not aimed at “crystallising” and distributing knowledge, but rather at providing the conditions in which knowledge is shared and new knowledge is created or exchanged in social networks, wikis or blogs.

The rest of the paper is structured as follows: the next section outlines the employed methodology, while the subsequent section summarises the findings of the literature review related to PKM, taking into account the knowledge management literature. The third section provides a discussion of the Web 2.0 phenomenon and its implications for Knowledge Management. The fourth section of the article discusses and compares PKM on Web 2.0 with traditional tools for KM and PKM. Finally, the paper concludes with findings and discusses future work. Web 2.0 enables a new model of PKM that involves formal and informal communication, collaboration and social networking tools. This new PKM model facilitates interaction, collaboration and knowledge exchanges on the web and in organisations.

\section{Methodology}

Methodologically, this study is primarily of a theoretically deductive nature. The analysis of the PKM field is based in the domain of Knowledge Management and Web 2.0 with a particular focus on the personal/individual dimension. This paper addresses the topic of PKM using Web 2.0 in order to explain the implications of Web 2.0 on PKM. The methodology for the review included two primary phases: selection of relevant articles and analysis. The selection phase aimed to identify and select articles related to PKM. The search for candidate articles based on the topic "personal knowledge management" was conducted primarily between January and March 2008 and afterwards revised in March 2009. We initially checked 
the Web of Science through its digital research libraries and found only seven journal articles based on the query of PKM as a topic. Then we extended the search by scanning articles on PKM on the ACM Digital Library and Google Scholar. Google Scholar found 843 papers, but with the broad scope the content was not always relevant. In addition to the documents retrieved based on these queries, we used background information as well as additional documents and examples in our analysis.

\section{Literature review}

PKM represents the sub-domain of knowledge management that emphasises the crucial importance of the individual in every knowledge process, proposing a model of knowledge management focused on the individual. A review of the literature indicates that the term "personal knowledge management” was introduced in 1999 in a working paper by Frand and Hixon (1999).

Knowledge is central to most of the daily tasks of knowledge workers, a large category of highly skilled professionals including consultants, lawyers, software developers, web designers, etc. Furthermore, knowledge is a source of competitive advantage not only at the organisational level but also at the individual level. Knowledge work is creative, communication-oriented and focussed across organisational boundaries (Maier et al., 2005). As knowledge is a key resource and arguably the most important one in our society, managing personal knowledge is strategically important. PKM focuses on the individual needs, interests and goals of learning, socialising, and completing work tasks effectively.

According to Davenport and Prusak (2000, p. 2), knowledge "is a fluid mix of framed experience, values, contextual information, and expert insight that provides a framework for evaluating and incorporating new experiences and information. It originates and is applied in the minds of knowers.” Nonaka and Takeuchi (1995) emphasise the personal dimension of knowledge by defining it as “a justified true belief”. Personal knowledge includes knowledge gained from memories, personal contacts and relationships, books, notes, documents, photographs, intuitions, what has previously been learned from colleagues, and what a person knows about everything in the world (Martin, 2000). Knowledge is also personal in the sense that people have different interpretations and different ways of reasoning. From the same information, different people may understand and infer different things. And by seeing and 
interpreting things differently, new knowledge is created. Knowledge is a term sometimes used interchangeably with data and information. Davenport and Prusak (2000, p. 2) define data as "a set of discrete, objective facts about events". The term data can be defined as the raw material that is processed and refined in order to generate information (Silver and Silver, 1989).

Information is data that has been processed into a form that is meaningful to the recipient (Davis and Olson, 1985). Information is data with meaning (Checkland and Scholes, 2000). There are several ways in which information can be personal, according to (Jones and Teevan, 2007):

- Information a person keeps for direct or indirect personal use.

- Information about a person kept by or under the control of others (e.g., health records).

- Information acquired by a person from publicly available sources (e.g., information learned from books, journals or the internet).

- Information directed to a person (e.g., by letter or email).

The management of personal information comprises the practice and study of the activities a person performs in order to acquire or create, store, organise, maintain, retrieve, use and distribute the information needed to meet goals and carry out roles and responsibilities (Jones, 2008).

Personal Information Management (PIM) focuses on the organisation and maintenance of personal information collections in which information items such as paper documents, electronic documents, notes, and emails are stored for later use and repeated re-use. PKM and PIM are distinct but related concepts. While PIM focuses on the management of information, PKM is centred on the management of personal knowledge. Knowledge workers can turn information into knowledge and generate new knowledge to stimulate problem solving and decision making. PKM may also be defined as a collection of processes that an individual needs to carry out in order to gather, classify, store, search, and retrieve knowledge in their daily activities (Grundspenkis, 2007).

Research on PKM is examined through different lenses and discussed from very different perspectives as summarised in Table 1.

Table 1. PKM literature overview 


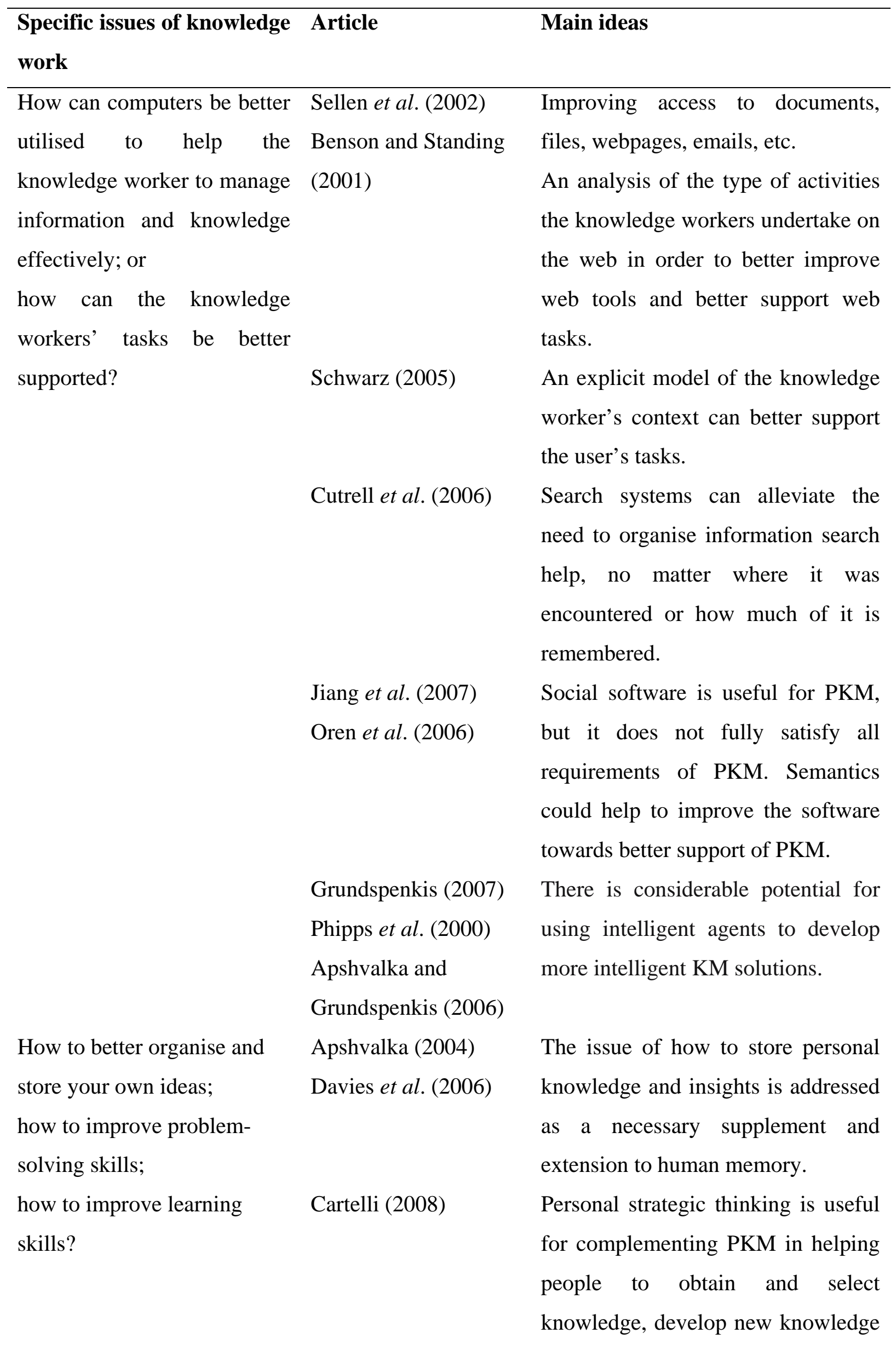


Li and Liu (2008)

Fang et al. (2008)

How to handle information overload?

What is the benefit of a PKM tool;

how can people be motivated to use PKM tools?
Kjellin and StenforsHayes (2007)

Lin et al. (2007) Völkel and Abecker (2008)

and improve problem solving skills. PKM tools may have far-reaching effects on e-learning, and the management of personal knowledge may be a key element for lifelong learning.

Dalsgaard et al. (2005) Three ways to cope with the increased load of information: propagating information, accepting information and blocking information.

The benefit of using a PKM system is the summarisation of successfully retrieved knowledge items. The cost is the sum of all effort of authoring and structuring knowledge.

Organisations should put more effort into amending knowledge management. The effects could be measured from a personal level.

How can Web 2.0 tools Kirchner et al. (2009) Web 2.0 tools simultaneously improve PKM? knowledge processes.

In the following, we provide an analysis of PKM based on the articles retrieved on this subject. An important part of PKM literature deals with issues related to information overload and personalisation techniques. Different frameworks and tools have been proposed to address the information overload problem (Alvarado and Ackermann, 2003; Dalsgaard et al., 2005), personalisation, contextualisation and customisation aspects (Hicks and Tochtermann, 2001; Razmerita, 2003, 2005a) or knowledge sharing issues (Kim and Kim, 2006; Roda et al., 2003). Some frameworks use intelligent agents and multi-agent systems to develop more intelligent features for KM systems (Apshvalka and Grundspenkis, 2006; Blanzieri et al., 2004; Grundspenkis, 2007; Phipps et al., 2000). According to Grundspenkis (2007), an 
intelligent organisational knowledge management system should operate like the human brain and fulfil functions of knowledge acquisition through sensors, knowledge formalisation, representation and storage in the knowledge space, knowledge inference, sharing, and use. Agent-based technology is necessary for addressing information processing problems, and/or in connection with information overload and/or for modelling the end user's knowledge or behaviour for a specific domain or helping users to adopt knowledge sharing practices (Roda et al., 2003). Kim and Kim (2006) offer a framework for collaborative knowledge sharing and recommendation based on taxonomic partial reputation on the personal knowledge directories. Their knowledge sharing and recommendation schemes depend on the autonomous and collaborative relations among users. Users can promote their reputation implicitly through their knowledge sharing activities.

Schwarz (2005) presents a framework that captures the knowledge worker's context. The context relies on the user's personal workspace and elicited resources (e.g., the user's own files, folders, or email contacts). Even if the user's behaviour and domain changes over time, the context will adapt automatically according to changes on the user's computer, i.e., new folders and new documents emerge, re-classification of documents occurs, etc. Context and personalisation features are important, as nowadays knowledge workers often use mobile or virtual offices with laptops, mobile phones or PDAs which need flexible personalised support from information and communication technologies.

PKM tools should help people to exchange pieces of information into something that can be systematically applied and help them to expand their personal knowledge (Frand and Hixson, 1999). Alpert (2005) discusses a web-based concept mapping tool as a way of managing personal knowledge. Apshvalka (2004) provides an overview of traditional tools used to manage personal knowledge. These tools include calendars, to-do lists, notebooks, and emails, as well as telephone and discussion forums. These tools create a clear delimitation between the personal dimension and collective dimension. Avery et al. (2001) introduce a framework where PKM is defined as a set of problem solving skills that have both a logical or conceptual, as well as a physical or hands-on, component. These skills are required for successful problem solving in daily knowledge work tasks. PKM skills are classified into seven categories: retrieving, evaluating, organising, collaborating around, analysing, presenting and securing information (Avery et al., 2001). 
The following section discusses the impact of Web 2.0 associated technologies on the process of managing and creating personal knowledge.

\section{The impact of Web 2.0 on managing personal knowledge}

In the last few years we have witnessed a transformation of the web from a static web towards a "living web" where the users bring content, collaborate and share knowledge. Web 2.0 tools include blogs, wikis, tags, RSS feeds, social bookmarking tools, and AJAX. Using Web 2.0 tools, people do not only passively consume information; rather, they are active contributors, even customising tools and technology for their use. Web 2.0 facilitates social networking and collaboration and therefore is also referred to as the Social Web. The underlying principle of the Social Web is to make use of the "wisdom of the crowd" and "user generated content". The wisdom of the crowd is a term coined by Surowiecki (2005) who argues that large groups of people are smarter than an elite few. No matter how intelligent they are, large groups of people are better at solving problems, fostering innovation, coming to wise decisions, and even predicting the future. In this highly interconnected, dynamic world, new ways of cultivating and exploiting knowledge sharing with customers, suppliers and partners are forcing companies to expand their knowledge management concepts and agendas (Mentzas et al., 2007). There is also the second phase of knowledge management where companies try to exploit a much richer form of knowledge assets, including blogs, wikis, and social networks, focusing on the social, collaborative dimension of Web 2.0.

This variety of communication tools available on Web 2.0 enables the introduction of a new KM model, also called KM 2.0 or Enterprise 2.0 (Kakizawa, 2007; McAfee, 2006; Shimazu and Koike, 2007). This model tries to better harness the use of collective intelligence, and thus accelerates the distribution of information. Web 2.0 introduces new communication tools that improve knowledge workers' collaboration and distribution of knowledge. "Wikis, blogs, group-messaging software and the like can make a corporate intranet into a changing structure built by distributed, autonomous peers - a collaborative platform that reflects the way the work really gets done” (McAfee, 2006, p.21). McAfee (2006) argues that Web 2.0 can generate strategic advantages for companies. Unlike classical KM tools, these new technologies focus not on capturing knowledge, but on enhancing knowledge work by facilitating collaboration. In addition, Web 2.0 tools are inexpensive and fairly easy to set up. 
Shimazu (2007) emphasises the fact that the KM model can expand collective intelligence by linking knowledge extraction from various communication tools and systems.

Social networking applications, such as Facebook, MySpace, LinkedIn, and Xing, have gathered large user communities in recent years, as shown in Figure 1. Social networking sites have become central points on the web for sharing personal information and socialising online. These applications bring together users who share similar interests and create communities around centres of interests.

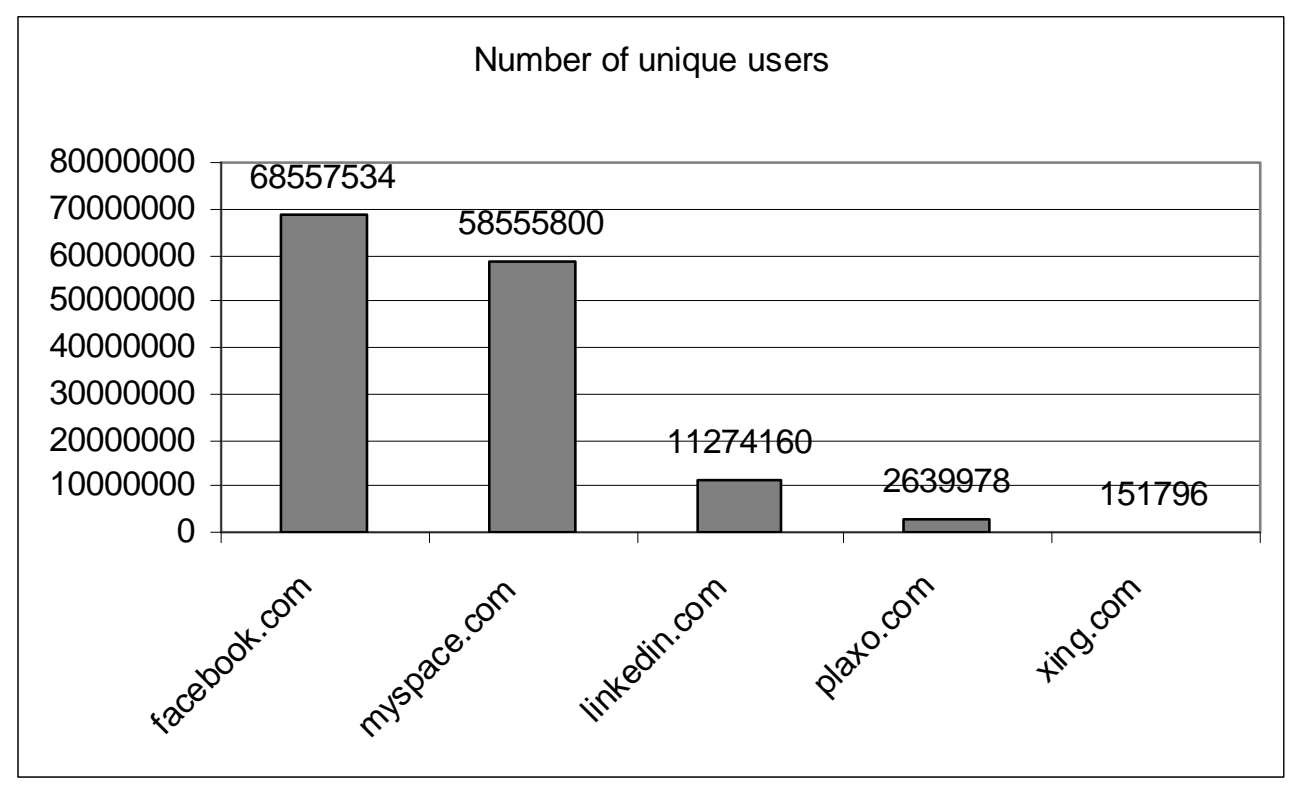

Figure 1. Number of active users of popular social networking sites in January 2009

Figure 1 shows the number of users registered as unique visitors in January 2009, according to data retrieved from compete.com. According to compete.com, these numbers count a person only once, no matter how many times they have visited a site. Social networks are moreover attracting an increasing number of users, as shown in Figure 2, with data collected from compete.com from January 2008 to January 2009. 


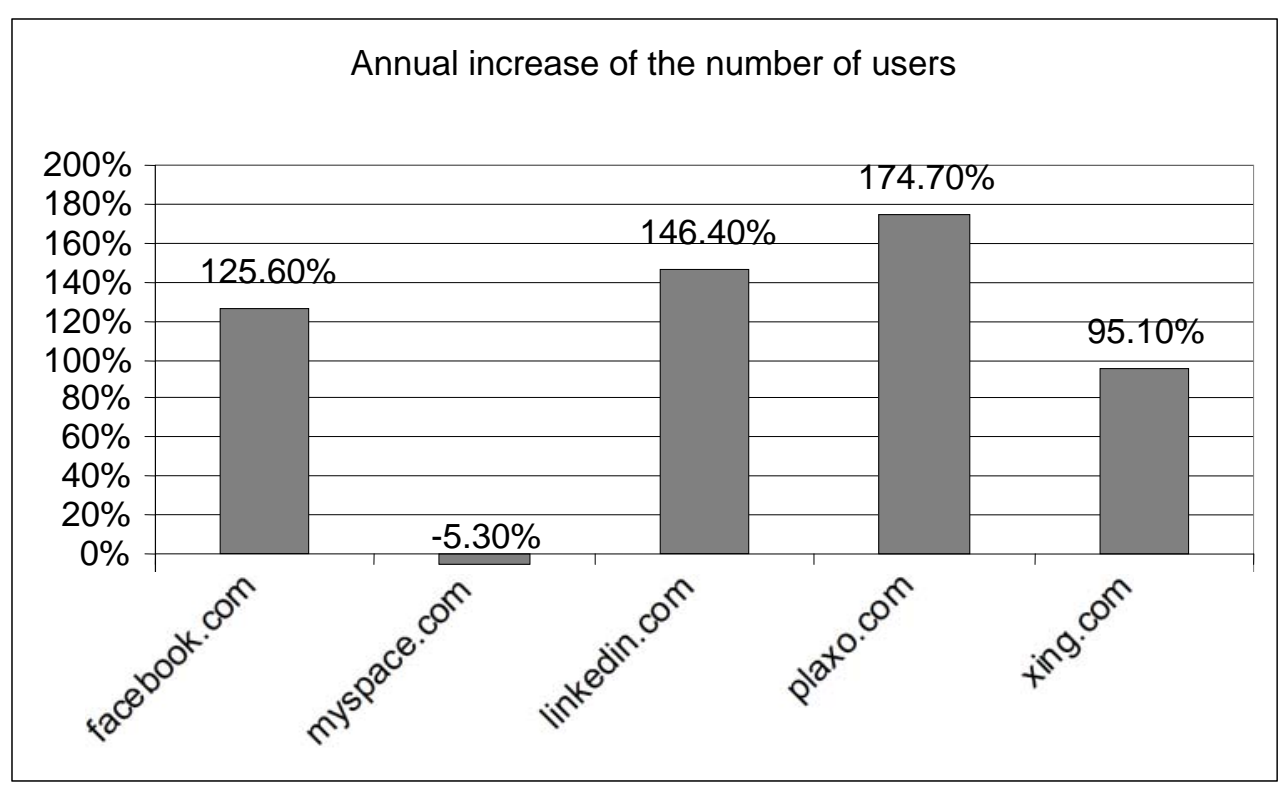

Figure 2. Annual growth of number of users, according to data retrieved from compete.com

Apart from their social dimension, social networking is also an enabler of informal learning. Breslin (2008) estimates that 75-80 percent of learning is done informally, and that 40-50 percent of employees access information and knowledge from social media sites. Some of the most successful services, such as Del.icio.us, Last.fm, Flickr, or YouTube, use social networking as a facilitator for exchange of items of interest (such as bookmarks, business contacts, music, photos, or videos).

When companies are concerned with security and privacy issues, they prefer to build and use proprietary solutions for social networks. For example IBM uses Beehive as an internal social networking site. Each user can design their own individual page and connect with other IBM employees. Personal data (family, hobbies) as well as information about current and previous projects and skills can be presented. Users can selectively hide some of their profile data. DiMicco et al. reported that Beehive users shared personal data more freely, since users knew that they .ere from the same company and that the site was behind the company firewall (DiMicco et al., 2008). They could connect with other employees whom they did not know personally, but with whom they shared similar interests. IBM employees who hardly knew each other increased their communication (2008). The authors reported that Beehive enabled the codification and sharing of personal knowledge for professional and personal purposes. It was found useful for advancing careers. By connecting with other employees who were in the 
same field of interest, browsing through their networks, and having discussions, new knowledge could be built up which could lead to career advancement. Last but not least, according to the interviewed IBM employees, awareness that the social network site was closed allowed for more honest and critical comments/discussions which could facilitate better learning opportunities (2008).

Blog posts or blogs are primarily textual and can vary widely in their content. They can be devoted to politics, news, and sharing opinions or dedicated to technical developments. Blog entries are usually maintained in chronological order, but are usually displayed in reverse chronological order. Nardi et al. (2004) identified five reasons why blogs are used:

1. to update others on activities and whereabouts;

2. to express opinions to influence others;

3. to seek others' opinions and feedback;

4. to "think by writing"; and

5. to release emotional tension.

Herring et al. (2004) define three types of blogs: personal journal, "filters" (because they select and provide commentary on information from other websites) and "knowledge logs". The majority of blogs (70 percent) are the online diary type. Zerfass and Bogosyan (2007) interviewed 600 internet users about their usage of blogs. Most (84 percent) of the interviewees believed that blogs are a good platform for sharing expert knowledge on different topics of interest. Bloggers are interested in reading new information, sharing knowledge and being connected with other users. While blog writers are more extroverted, blog readers are more consumerist. The use of blogs and semantic blogs has recently been associated with a decentralised form of Knowledge Management (Cayzer, 2004).

Wiki applications facilitate collaborative editing supported by revision mechanisms that allow the monitoring of changes. Wiki technology can be used as a community platform but also as a personal authoring environment. Wiki was developed in 1994 by Ward Cunningham. Wiki comes from the Hawaiian word "wiki-wiki" meaning fast. Evaluating the quality of contributions in such collaborative authoring environments is a challenging task (Korfiatis et al., 2006). However based on the "wisdom of the crowd" principle one collects and aggregate enough data until there is a consistently reliable answer. Oren et al. (2006) acknowledge that wikis are successful for information collection, but point out that they do not fully satisfy the requirements of PKM. A semantic wiki allows users to make formal descriptions of resources 
by annotating the pages that represent those resources. Whereas a regular wiki enables users to describe resources in natural language, a semantic wiki allows users to additionally describe resources in formal language. Semantic wikis augment ordinary wikis by using the metadata annotations, and thus may offer better information retrieval and knowledge reuse.

\section{Tools for PKM on the Social Web}

Based on the survey of existing Web 2.0 tools, PKM tools can be classified into six categories:

1. Personalised web pages that enhance organising and presenting information and sharing it with others. An example of a personalised webpage service is the AJAX-based netvibes (www.netvibes.com). Upon entry, a user may create a personalised website which can be shared with other users. Netvibes webpages are organised in tabs. Each tab can include various user-defined modules. Netvibes Ecosystem (eco.netvibes.com) includes a variety of widgets, such as calendars, translators, mapping or financial applications. The user can also choose wallpaper and sort all themes according to preference and need. Ginger is a new version of netvibes where social network features are included. The website enables users to access their history of activities or their friends' activities. People with similar favourites in their profiles are recommended as possible friends. Their public personal pages are accessible to the matches who can add them as friends later. Other examples of Web 2.0 tools enabled websites that can be personalised are PageFlake, Newsgator, Shtr, iGoogle, MyYahoo!, or Live.Com. These sites allow people to create personalised web pages by subscribing to specific content through RSS feeds and aggregating different types of information (e.g., blogs, favourite websites, weather forecasts), widgets or applications (e.g., calendars, dictionaries) in one place. This integration of different information sources facilitates access to information and the possibility of creating knowledge.

2. Personalised search tools that provide for retrieving and sharing of information. Swicki (www.eurekster.com) is a personalised search portal on topics of one's choice powered by a community. A Swicki learns from the community's search behaviour; thus, it is easier to find something interesting.

3. Social bookmarking that provides a simple way for a community of people to share bookmarks of internet resources. Heystaks (www.heystaks.com) is tool that offers the collection, classification and sharing of web search results. Search results can be added 
to one's own lists called stacks, but it is also possible to join existing lists and benefit from others. Lists can be declared private or public, and can be shared with colleagues and friends. Links can be evaluated to indicate their quality to others. Using Heystaks, the management of bookmarks becomes a social activity.

4. Personalised live discussion forums that assist in analysing, evaluating, presenting, and sharing information. With Tangler (www.tangler.com), it is possible to create a live discussion forum and to share discussions with others.

5. Virtual worlds that encourage sharing of information. SecondLife (http://www.secondlife.com/) or Vastpark (www.vastpark.com) are 3D platforms that allow users to create their own virtual world that they can own and share with others. It can be used for 3D gaming, building 3D presentations or creating social networks in shared worlds where users communicate, cooperate, learn and collaborate.

6. Blogs and wikis that support editing, presenting and organising information or knowledge by individuals or in collaboration with others. A special category of wikis is personal wikis. They allow people to organise information on their desktop or mobile computing device in a manner similar to normal wikis. They are installed as a standalone version and can be seen as personal information managers. An example of a personal wiki is Pimki (pimki.rubyforge.org) which includes mind maps, search functions or todo lists.

Table 2 extends the traditional PKM tools classification proposed by Apshvalka (2004) with the Web 2.0 tools and summarises the characteristics of each type of tool in relation to key knowledge oriented processes such as knowledge creation, knowledge codification, knowledge sharing, collaboration and organisation of knowledge ( $\mathrm{X}$ indicates that a characteristic is strongly supported, whereas an $\mathrm{x}$ indicates a characteristic is supported at a certain level only).

Table 2. Traditional and Web 2.0 tools for Personal Knowledge Management

\begin{tabular}{|c|c|c|c|c|c|c|c|}
\hline & & Tools & Creation & Codification & Sharing & Collaboration & Organisation \\
\hline$n$ & & Calendar & & $\mathrm{X}$ & & & $\mathrm{x}$ \\
\hline$\stackrel{8}{\mathscr{E}}$ & $\Sigma$ & Chat & $\mathrm{x}$ & & $\mathrm{x}$ & & \\
\hline อี & $\underline{a}$ & Diary & $\mathrm{x}$ & $\mathrm{x}$ & & & $\mathrm{x}$ \\
\hline 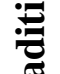 & 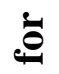 & File system & & $\mathrm{x}$ & $\mathrm{x}$ & & $\mathrm{x}$ \\
\hline$E$ & & Notebook & $\mathrm{x}$ & $\mathrm{x}$ & & & $\mathrm{x}$ \\
\hline
\end{tabular}




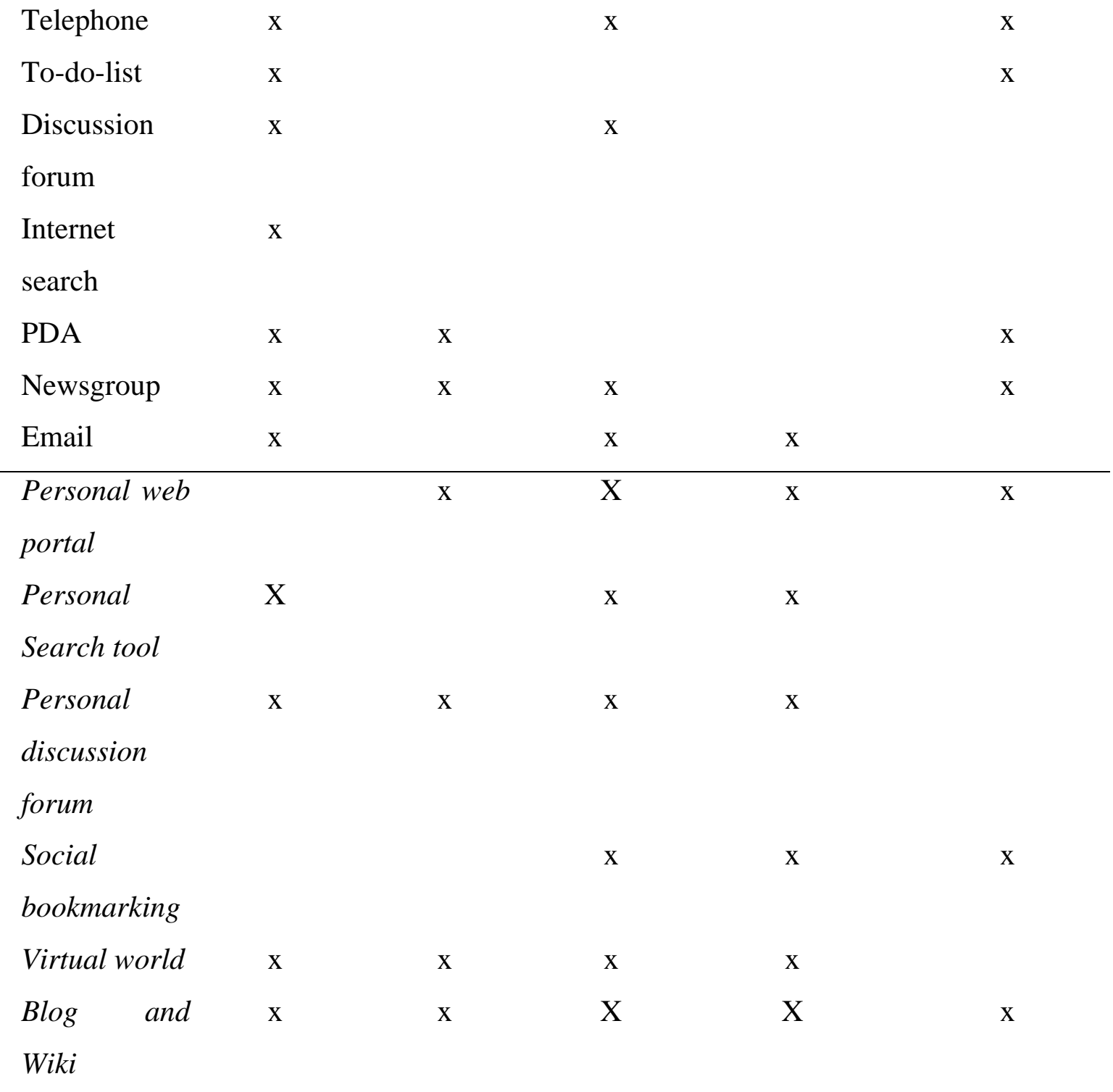

As can be observed in Table 2, in contrast to traditional PKM tools, PKM 2.0 facilitates and supports communication, social interaction and collaboration. Web 2.0 tools enable a new model for PKM that enhances management of knowledge at both the personal and collective level (Kirchner et al., 2009). Furthermore, Web 2.0 tools facilitate new forms of knowledge sharing and interaction at the individual and collective level, harnessing collective knowledge through formal and informal communication, collaboration and social networking.

Social networks, blogs and wikis become important tools for managing knowledge not only at the personal level, but especially at the organisational level (Bitkom, 2007). An example of successful blog and wiki use in companies is IBM. Within IBM, 15 percent of the employees run their own company-internal or public blogs, and half of the employees regularly write 
more than 143,000 entries in 8800 wikis (Schütt, 2007). The company encourages its staff members to share their knowledge with others. Each employee can introduce themselves as an expert in a certain field, can share expert knowledge with others and collaborate with them. In the IBM Blogging Guidelines (IBM Corporation, 2005), each blogger is required to use their real name, to acknowledge working for IBM, and to advance a personal opinion.

Another example is Synaxon AG in Germany (soc.wiki.synaxon.de), a company with 140 employees, most of whom have technical knowledge. All organisational knowledge is collected in a wiki with more than 5200 web pages: from partner contracts to job openings, the documentation of all projects, or the explanation of technical terms. Feedback from company employees is positive, as all activities are transparent, and staff can make suggestions for improvements. Compared with email, people have access to more information about departments or projects in which they are not involved. They can select the wiki sites that they are interested in and if these sites are updated, receive automatic information (Bergmann, 2007).

McKinsey (2007) conducted a survey of Web 2.0 technology use in business with a sample of 2,847 executives worldwide. Over 75 percent of the respondents said that their companies made investments in Web 2.0 technologies because they were important for supporting market position and for addressing customer demands. However, Web 2.0 tools are not widely used in enterprises today. The 451 Group (Reidy, 2008) surveyed 2,081 IT and business managers worldwide about their blog, wiki and social bookmark usage. The survey revealed that only 25 percent of them used these Web 2.0 tools to collaborate with colleagues, business partners or customers. Moreover, 58 percent of interviewees did not have any plans to use social software in their enterprises in the near future.

\section{Discussion}

This section provides an analysis of the evolution and distinguishing characteristics of the PKM concept, based on the literature survey and in relation to the development of new tools available on Web 2.0. We argue that the evolution of the PKM concept can influence and may be associated with the evolution of the KM concept. 
Despite the fact that managing knowledge at an individual level represents a crucial issue for knowledge workers and can be associated with PKM, PKM has received little attention within the knowledge management community. The review of the literature indicates very few articles by knowledge management scholars that cover PKM and a very limited diffusion of the PKM concept. As already mentioned in the methodology section, we found only seven journal articles on the PKM topic on the Web of Science. The limited interest may originate in the difficulty of supporting people to manage their knowledge at an individual level, or how difficult it is for organisations to help individuals in this particular aspect, or the association of the PKM concept with many PIM tools (e.g., word processors, calendars) that employees use on a daily basis (Kirchner et al., 2009). This last hypothesis is confirmed by the much larger number of articles found on the ACM Digital Library and Google Scholar. PKM is investigated by the HCI community and computer science scholars from many different angles and covers a large number of issues for knowledge work, as summarised in Table 1.

New technological capabilities offered by the Social Web bring new perspectives and tools for KM and PKM. Web 2.0 tools support the simultaneous management of individual and collective knowledge processes along with social processes. People can organise bookmarks using social bookmarking tools and share knowledge, personal experiences and views using blogs or wikis on the internet or an intranet. These processes are important for the individuals, but they may also contribute to collective knowledge.

The first phase of PKM enables people to capture, codify, share and organise knowledge, using traditional tools such as calendars, to-do lists, newsgroups, etc., as summarised in Table 2. However, the first phase of knowledge management is when companies' institutionalised knowledge creation, storage and sharing through internal KM initiatives is complete (Mentzas et al., 2007). In the first phase of KM (KM1.0), KM tools support knowledge capturing, storing, organising and sharing. The four most popular KM technologies involve creating: intranets, databases and later data warehousing, decision-support tools, and groupware. The main challenges are to nurture knowledge sharing, knowledge flow, knowledge creation and codification of tacit knowledge. Knowledge is the most valuable resource for a company, but the most important type of knowledge resides in people’s heads; it is “embrained” (Blackler, 1995). People are reluctant to "brain dump" what they know for others because knowledge is a source of power. Further, knowledge does not automatically organise itself into knowledge management tools and systems. Knowledge sharing and creation require time and effort on 
top of the daily activities of knowledge workers who are the main contributors to the system. It requires a critical mass of users in order to be useful, and therefore active involvement of the users is a critical factor for the success of knowledge management solutions (Kirchner et al., 2008; Razmerita, 2007). Convincing people to change their behaviour and to adopt knowledge sharing behaviours is one of the most challenging tasks for KM (Roda et al., 2003). Other specific challenges of KM systems are how to: motivate people to create knowledge and submit new knowledge assets into the system, stimulate collaboration and knowledge sharing between knowledge workers irrespective of their location, alleviate information overload, simplify business processes and work tasks, and organise knowledge semantically. Knowledge contribution involves maintaining and nurturing a system mainly for the benefit of the organisation. This often results in a system of little use for organisations or even ends in the failure of many KM initiatives (Schultze and Boland, 2000).

However Web 2.0 brings new possibilities and tools not only to PKM, but also to the management of information and knowledge in organisations. Social software supports active social networking processes and a community model to foster knowledge sharing and collaboration. Web 2.0 helps bridge the two contrasting views of the KM process (Newell et al., 2002): the cognitive and community models. The community model emphasises the fact that knowledge is continuously recreated and reconstructed through dynamic, interactive and social networking activity. Organisational theory highlights the fact that knowledge is embedded and constructed through social interactions (Blackler, 1995; Nonaka, 2007; Nonaka and Takeuchi, 1995).

Web 2.0 technology and its associated tools enable a new KM model known as KM 2.0. This model tries to harness the collective intelligence through formal and informal communication and social networking among employees. People are now publishing because they can achieve the status of leaders and evangelists (Thom-Santelli et al., 2008) rather than seeking information for themselves or because it is compulsory. Furthermore, people can connect and collaborate easily with fellow employees. Blogs, social bookmarks and wikis represent new repositories of information and knowledge for personal and organisational purposes. High quality contributions are assured not only by guidelines, but also by reputation and rating the contributions. Through social software, employees are more motivated to share knowledge with others in the same company (Kirchner et al., 2008). However the value of these tools is more information centric than social (DiMicco et al., 2008). 
The use of Web 2.0 tools for knowledge management enables companies to reap large benefits with lower costs than the traditional KM system. Further, by promoting products and services, companies can reach many more users and receive valuable feedback more quickly. Companies have to decide whether they want to build their own internal proprietary solutions with blogs, wikis, social networks or with the use of existing tools. Although anyone can use social software and edit a blog or a wiki, not everybody does. Effective social structures may create incentives and guide fruitful collaborations. It depends on the number of employees/customers that they have, because a critical mass of users is necessary to implement a successful system (Breslin, 2008).

Web 2.0 can also have a disruptive impact. Employees can spend a lot of time with blogs and thus a loss of productivity can occur. Global Secure Systems (2008) surveyed 776 office workers in the UK regarding their social network activities, and reported that 41 percent of employees were spending 30 minutes per day on Facebook or MySpace, which cost six million pounds per year.

\section{Conclusions and outlook}

The Web 2.0 era has emerged as a shift of perspective from a world of plentiful information that has to be searched using powerful search engines to a world in which the social process has become central for identification and access to information and knowledge. In this new world, a variety of tools have been developed to better manage the social capital (with social networking systems such as Plaxo, LinkedIn), to communicate with others (including customers) more effectively (with blogs, microblogs), and/or to harness collective intelligence (with systems such as wikis and social bookmarking).

PKM is not a well investigated concept and Web 2.0 tools provide new technological capabilities to support PKM, social processes and collaboration. This paper suggests that Web 2.0 tools provide an opportunity for new developments of the PKM concept, and open debate over the benefits and limitations of existing practices and the opportunities and threats provided by these tools. In particular, this paper discusses these new approaches developed with the objective of operationalising this social perspective in the context of managing personal knowledge. We argue that the focus has begun to shift from organisational 
knowledge management towards personal knowledge management. The vision of PKM is no longer just about extracting knowledge from experts, codifying it and making it widely available to others via databases, as in a first generation knowledge management system. Instead PKM, using Web 2.0 tools, facilitates the whole life cycle of knowledge processes in a human context. Web 2.0 enables a new model of PKM that contributes to collective intelligence through formal and informal communication, collaboration and social networking tools. This new PKM model facilitates virtual interaction, social processes, collaboration and knowledge exchanges on the web and in organisations. Personal and collective knowledge are two faces of complex knowledge management processes that are not opposed but have the potential of making the management of knowledge more efficient both at individual and collective levels (Kirchner et al., 2009).

PKM is not a single individual system, but a set of tools and systems (such as blogs, discussion forums, social networking systems, etc.) that are used for managing knowledge and/or personal/professional relationships. A characteristic of such systems is the fact that they are open and designed to invite collaboration and to facilitate social interaction. Externalisation of personal knowledge is either self-initiated (blogs, wikis) or requested by others (Yahoo! Answers, LinkedIn Answers). However, the fragmentation of these different systems and their lack of interoperability constitute important roadblocks towards an optimal usage of these tools for PKM. Privacy concerns are also potential barriers for the rapid mass adoption of these tools. In certain cases the diffusion of knowledge or information from the personal sphere to the collective sphere without one's intention and knowledge is an important concern (Gross et al., 2005; Kirchner et al., 2009). Even the utilisation of an intranet as a corporate management infrastructure may not alleviate this problem. Furthermore, despite using Web 2.0 tools it is still difficult to find the right piece of information. Better search functionalities and sorted entries are an issue that needs to be addressed in further development. Semantic Web technologies will enhance Web 2.0 tools and their associated data with semantic annotations and semantic-enhanced knowledge representations, thus enabling a better automatic processing of data which in turn will lead to enhanced search mechanisms, a better management of tacit knowledge and increased overall efficiency of the actual KM and PKM tools. In the next few years a new generation of tools, KM 3.0 and PKM 3.0, associated with a new generation of semantic-enhanced KM tools may proliferate, including semantic blogs (Cayzer, 2004), semantic wikis (Oren et al., 2006), semantic social networks (Breslin and Decker, 2007) or semantic-enhanced user support (Razmerita, 2005a). 


\section{References}

Alpert, S.R. (2005), “Comprehensive mapping of knowledge and information resources: the case of Webster”, in Tergan, S.-O. and Keller, T. (Eds.), Knowledge and Information Visualization: Searching for Synergies Vol. 3426, Springer, Berlin, pp. 220-37.

Alvarado, T. and Ackermann, K. (Eds.). (2003), Surviving the Information Explosion: How People Find Their Electronic Information, Massachusetts Institute of Technology Artificial Intelligence Lab, Cambridge, MA.

Apshvalka, D. (2004), "Personal Knowledge Management”, in Remenyi, D. (Ed.), Proceedings of the 11th European Conference on Information Technology Evaluation, Amsterdam,11-12 November, Academic Conferences Limited, Reading, UK, pp. 1722.

Apshvalka, D. and Grundspenkis, J. (2006), "Personal Knowledge Management and Intelligent Agent Perspective”, in Proceedings of the 14th International Conference on Information Systems Development, Karlstad, Sweden. pp. 219-30.

Avery, S., Brooks, R., Brown, J., Dorsey, P., and O’ Connor, M. (2001), “Personal knowledge management: framework for integration and partnerships”, in Smith, P. (Ed.), Proceedings of the Association of Small Computer Users in Education Conference at North Myrtle Beach, SC, 10-14 June, pp. 29-39.

Benson, S. and Standing, C. (2001), “Effective knowledge management: knowledge, thinking and the personal-corporate knowledge nexus problem", Information Systems Frontiers, Vol. 3 No. 2, pp. 227-38.

Bergmann, J. (2007), “Die gläserne Firma”, Brand Einz, No. 3, pp. 109-15.

Bitkom (2007), "Wichtige Trends im Wissensmanagement 2007 bis 2011", [online], available at: $\quad$ www.bitkom.org/files/documents/Trendreport_WM_zur_KnowTech2007.pdf (accessed 1 September 2009).

Blackler, F. (1995), "Knowledge, knowledge work and organizations: an overview and interpretation”, Organization Studies, Vol. 16 No. 6, pp. 1021-46.

Blanzieri, E., Giorgini, P., Giunchiglia, F. and Zanoni, C. (2004), "Implicit culture-based personal agents for knowledge management”, Agent-Mediated Knowledge Management, Vol. 2926, pp. 245-61. 
Breslin, J. (2008), “Social network service for enterprise use”, [online], available at: http://socialmedia.net/2008/02/04/social-networking-services-for-enterprise-use-2/ (accessed 31 March 2009).

Breslin, J., and Decker, S. (2007), “The Future of Social Networks on the Internet: The Need for Semantics”, IEEE Internet Computing Magazine, Vol. 11 No. 6, pp. 86-90.

Cartelli, A. (2008), “e-Learning and e-Citizenship between PKM and PST”, in Williams, R. and Remenyi, D. (Eds.), 7th European Conference on e-Learning, Agia Napa, Cyprus, Academic Publishing International, pp. 169-77.

Cayzer, S. (2004), “Semantic blogging and decentralized knowledge management”, Communications of the ACM, Vol. 47 No. 12, pp. 47-52.

Checkland, P. and Scholes, J. (Eds.), (2000), Soft Systems Methodology, Wiley, Chichester.

Cutrell, E., Dumais, S. and Teevan, J. (2006), "Searching to eliminate personal information management”, Communications of the ACM, Vol. 49 No. 1, pp. 58-64.

Dalsgaard, P., Eriksson, E. and Hansen, L.K. (2005), "Rethinking information handling: designing for information offload”, in Bertelsen, O.W., Bouvin, N.O., Krogh, P.G. and Kyng, M. (Eds.), Proceedings of the 4th Decennial Conference on Critical Computing: Between Sense and Sensibility, Aarhus, Denmark, 20-24 August, pp. 1614.

Davenport, T.H. and Prusak, L. (2000), “Working knowledge: how organizations manage what they know”, Ubiquity, Vol. 1 No. 24, p. 2.

Davies, S., Allen, S., Raphaelson, J., Meng, E., Engleman, J.K.R. and Lewis, C. (2006), "Popcorn: the personal knowledge base", in Proceedings of the 6th Conference on Designing Interactive Systems, University Park, PA, 26-28 June, ACM, New York, pp. 150-9.

Davis, G.B. and Olson, M.H. (Eds.). (1985), Management Information Systems, McGrawHill, New York.

DiMicco, J., Millen, D., R., Geyer, W., Dugan, C., Brownholtz, B. and Muller, M. (2008), “Motivations for social networking at work", paper presented at the ACM Computer Supported Cooperative Work, San Diego, ACM Press, New York, pp. 711-720.

Efimova, L. (2004), “Discovering the iceberg of knowledge work: a weblog case”, paper presented at the Fifth European Conference on Organisational Knowledge, Learning and Capabilities, Boston, 17-19 March.

Fang, R.-J., Lin, C.-C., Chang, Y.-F., Tsai, H.-L. and Chang, Y.-S. (2008), “Integrating KM learning activities into business management curriculum instruction”, in Proceedings 
of the 8th WSEAS International Conference on Multimedia Systems and Signal Processing, Hangzhou, China, 6-8 April, pp. 164-9.

Frand, J. and Hixson, C. (1999), "Personal knowledge management: who, what, why, where, when, and how", Working paper, [online], available at: http://www.anderson.ucla.edu/faculty/jason.frand/researcher/speeches/PKM.htm (accessed 1 September 2009).

Global Secure Systems (2008), “Social networking sites cost UK plc £6.5 billion in lost productivity", [online], available at: www.gss.co.uk/press/?\&id=17 (accessed 1 September 2009).

Gross, R., Acquisti, A. and Heinz, H.J. (2005), "Information revelation and privacy in online social networks”, paper presented at the ACM Workshop on Privacy in the Electronic Society, ACM Press, New York, pp. 71-80.

Grundspenkis, J. (2007), “Agent based approach for organization and personal knowledge modelling: knowledge management perspective”, Journal of Intelligent Manufacturing, Vol. 18 No. 4, pp. 451-7.

Herring, S., Scheidt, L., Bonus, S. and Wright, E. (2004), “Bridging the gap: a genre analysis of weblogs”, in Proceedings of the 37th Annual Hawaii International Conference on System Sciences, Big Island, Hawaii, 5-8 January, i.

Hicks, D. and Tochtermann, K. (2001), "Personal digital libraries and knowledge management”, Journal of Universal Computer Science, Vol. 7 No. 7, pp. 550-65.

IBM Corporation (2005), “IBM blogging policies and guidelines publication”, [online], available at: http://www.snellspace.com/IBM_Blogging_Policy_and_Guidelines.pdf (Accessed 31 March 2008).

Jiang, K., Gao, Z., Phuc, N.H. and Ohshima, N. (2007), "Research on the application model about social software's combination in personal knowledge management”, inKaminishi, K. and Duysters, G. (Eds.), Proceedings of the 4th International Conference on Innovation and Management, Ube, Japan, 5-6 December, pp. 1972-6.

Jones, W. and Teevan, J. (2007), Personal Information Management, University of Washington Press, Seattle.

Jones, W.P. (Ed.). (2008), Keeping Found Things Found, Morgan Kaufmann, Amsterdam.

Kakizawa, Y. (2007), "In-house use of Web 2.0: Enterprise 2.0”, NEC Technical Journal, Vol. 2 No. 2, pp. 46-9. 
Kim, D.H. and Kim, S.J. (2006), "Framework for collaborative knowledge sharing and recommendation based on taxonomic partial reputations”, Knowledge Science, Engineering and Management, Vol. 4092, pp. 190-201.

Kirchner, K., Razmerita, L. and Nabeth, T. (2009), "Personal and collective knowledge management in the Web 2.0: two faces of knowledge management”, paper presented at the 9th International Conference on Innovative Internet Community Systems, Jena, Germany. in press.

Kirchner, K., Razmerita, L. and Sudzina, F. (2008), "New forms of interaction and knowledge sharing on Web 2.0”, in Lytras, M., Damiani, E. and Ordonez De Pablos, P. (Eds.), Web 2.0: The Business Model, Springer, Berlin, pp. 21-37.

Kjellin, H. and Stenfors-Hayes, T. (2007), "Personal knowledge management as an icebreaker - motivating contributions to knowledge management systems”, in Cardoso, J., Cordeiro, J. and Filipe, J. (Eds.), Proceedings of the Ninth International Conference on Enterprise Information Systems, Funchal, Portugal,12-16 June, pp. 76-81.

Korfiatis, N., Poulos, M., and Bokos, M. (2006), "Evaluating authoritative sources using social networks: an insight from Wikipedia”, Online Information Review, Vol. 30 No. 3, pp. 252-62.

Li, W. and Liu, Y. (2008), "Personal knowledge management in e-learning era”, in Pan,, Z., Zhang, X., ElRhalibi, A., Woo, W. and Li, Y. (Eds.), Proceedings of the 3rd International Conference on E-Learning and Games (Edutainment 2008), Nanjing, China, 25-27 June, ACM, New York, pp. 200-5.

Lin, C.-C., Hsieh, P.-J. and Shyu, J.Z. (2007), "The study of the KM gaps between personal knowledge management and enterprise knowledge management”, in Chen, J., Xu, Q. and Wu, X. (Eds.), Proceedings of the Fifth International Symposium on Management of Technology, Hangzhou, China, 1-3 June, pp. 602-5.

Maier, R., Haedrich, T. and Peinl, R. (Eds.). (2005), Enterprise Knowledge Infrastructures, Springer, Berlin.

Maier, R. and Sametinger, J. (2004), "Personal knowledge management in a peer-to-peer environment”, in Remenyi, D. (Ed.), Proceedings of the 5th European Conference on Knowledge Management, Paris, 30 September - 1 October, pp. 505-14.

Martin, J. (2000), "Personal knowledge management: the basis for corporate and institutional knowledge", in Martin, J. and Wright, K. (Eds.), Managing Knowledge: Case Studies in Innovation, Spotted Cow Pres, Edmonton. 
McAfee, A.P. (2006), "Enterprise 2.0: the dawn of emergent collaboration”, MIT Sloan Management Review, Vol. 47 No. 3, pp. 1-28.

McKinsey (2007), “How businesses are using Web 2.0: a McKinsey Global Survey”, unpublished manuscript.

Mentzas, G., Kafentzis, K. and Georgolios, P. (2007), “Knowledge services on the Semantic Web”, Communications of the ACM, Vol. 50 No. 10, pp. 53-8.

Nabeth, T., Angehrn, A. and Roda, C. (2002), “Towards personalized, socially aware and active knowledge management systems”, in Stanford-Smith, B., Chiozza, E. and Edin, M. (Eds.), Proceedings of E-business and E-work - Challenges and Achievements in E-business and E-work, IOS Press, Amsterdam, Vol. 2, pp. 884-91.

Nardi, B., Schiano, D. and Gumbrecht, M. (2004), "Blogging as social activity, or, Would you let 900 million people read your diary?” in Proceedings of the Conference on Computer-Supported Cooperative Work, Chicago, ACM, New York, pp. 222-31.

Newell, S., Robertson, M, Scarbrough, H. and Swan, J (Eds.). (2002), Managing Knowledge Work, Palgrave Macmillan, Basingstoke.

Nonaka, I. (2007), “The knowledge-creating company”, Harvard Business Review, Vol. 85 Nos. 7/8, pp. 162-71.

Nonaka, I. and Takeuchi, H. (Eds.). (1995), The Knowledge-Creating Company: How Japanese Companies Create the Dynamics of Innovation, Oxford University Press, New York.

O’Reilly, T. (2005), "What is Web 2.0? Design patterns and business models for the next generation of software", [online], available at: www.oreillynet.com/pub/a/oreilly/tim/news/2005/09/30/what-is-web-20.html (accessed 1 September 2009).

Oren, E., Volkel, M., Breslin, J.G. and Decker, S. (2006), "Semantic wikis for personal knowledge management”, Proceedings of Database and Expert Systems Applications Vol. 4080, pp. 509-18.

Phipps, M., Mork, J. and McSherry, M. (2000), “Using intelligent agents and a personal knowledge management application”, Agent Systems, Mobile Agents and Applications Vol. 1882, pp. 262-74.

Razmerita, L. (2003), User Models and User Modeling in Knowledge Management Systems: An Ontology-based Approach, Paul Sabatier University, Toulouse. 
Razmerita, L. (2005a), "User modeling and personalization of knowledge management systems”, in Chen, S.Y. and Magoulas, G.D. (Eds.), Adaptable and Adaptive Hypermedia, Idea Group Publishing, Hershey, PA, pp. 225-45.

Razmerita, L. (2005b), “Exploiting semantics and user modeling for enhanced user support”, [Electronic Version]. Proceedings of HCI International 2005, CDROM.

Razmerita, L. (2007), “Ontology-based user modeling for knowledge management systems”, in Sharman, R., Kishore R. and Ramesh, R. (Eds.), Ontologies: A Handbook of Principles, Concepts and Applications in Information Systems, Vol. 14, Springer, Boston, pp. 635-64.

Reidy, K. (2008), “The New Social Order - Trends, developments and opportunities in enterprise social software [online], www.451group.com/reports/executive_summary.php?id=499 (accessed 31 March 2008).

Roda, C., Angehrn, A., Nabeth, T. and Razmerita, L. (2003), "Using conversational agents to support the adoption of knowledge sharing practices”, Interacting with Computers, Vol. 15 No. 1, pp. 57-89.

Schultze, U. and Boland, R.J. (2000), “Knowledge management technology and the reproduction of knowledge work practices”, The Journal of Strategic Information Systems, Vol. 9 No. 2, pp. 193-212.

Schütt, P. (2007), “Blogs und Wikis erfolgreich im Unternehmen einsetzen”, Computerzeitung, 5 June.

Schwarz, S. (2005), “A context model for personal knowledge management applications”, Modeling and Retrieval of Context, Vol. 3946, pp. 18-33.

Sellen, A.J., Murphy, R. and Shaw, K.L. (2002), "How knowledge workers use the web”, in Proceedings of the SIGCHI Conference on Human Factors in Computing Systems: Changing our World, Changing Ourselves, Vol. 1, 20-25 April, ACM, New York, pp. 227-34.

Shimazu, H., and Koike, S. (2007), "KM2.0: business knowledge sharing in the Web 2.0 age”, NEC Technical Journal, Vol. 2 No. 2, pp. 50-4.

Silver, G.A. and Silver, M.L. (Eds.) (1989), Systems Analysis and Design, Addison-Wesley, Reading, MA.

Surowiecki, J. (Ed.), (2005), The Wisdom of the Crowds, Anchor Books, New York. 
Thom-Santelli, J., Muller, M.J. and Millen, D.R. (2008), “Social tagging roles: publishers, evangelists, leaders”, in Proceedings of the Twenty-sixth Annual SIGCHI Conference on Human Factors in Computing Systems, Florence, ACM, New York, pp. 1041-4.

Thomas, J.C., Kellogg, W.A. and Erickson, T. (2001), “The knowledge management puzzle: human and social factors in knowledge management”, IBM Systems Journal, Vol. 40 No. 4, p. 863.

Völkel, M. and Abecker, A. (2008), "Cost-benefit analysis for the design of personal knowledge management systems”, in Cordeiro, J. and Filipe, J. (Eds.), Proceedings of the Tenth International Conference on Enterprise Information Systems, Barcelona, Springer, Berlin, pp. 95-105.

Wright, K. (2005), "Personal knowledge management: supporting individual knowledge worker performance”, Knowledge Management Research and Practice, Vol. 3 No. 3, pp. 156-65.

Zerfass, A. and Bogosyan, J. (2007), "Blogstudie im Internet - Blogs als neues Recherche tool (Ergebnisbericht)”,unpublished manuscript, Leipzig. 